- There is a high comorbidity of smoking and mental and behavioural disorders.

- Smoking affects blood levels of some psychiatric medications and mental and behavioural disorders affect quitting smoking.

- Smoking cessation management for patients with mental and behavioural disorders may be outside the professional training of dentists.

- Patients with mental and behavioural disorders who smoke should be identified and referred for medically supervised cessation management.

\title{
The dental role in smoking cessation advice for patients with mental and behavioural disorders - time for improvement?
}

\author{
R. A. Baker ${ }^{1}$
}

The past few years have seen an increasing emphasis upon the role of the dental team in smoking cessation. The recent advances in knowledge of the level and role of tobacco use in patients with mental and behavioural disorders, the biological factors involved and the influences of tobacco on psychiatric medication metabolism and side effects has not been reflected in dental postgraduate education. Perhaps it is time for an evidence based improvement in care standards by referring these patients for specialist cessation advice?

\section{INTRODUCTION}

Today, smoking is established as a recognised cause of general diseases such as cancer, lung disease, coronary heart disease and stroke. It is also associated with oral diseases such as oral cancer, periodontal disease and premature tooth loss. As such, smoking is thought to be the largest single preventable cause of death and disability in the UK.

Smoking cessation delivers major health improvements to the individual and it is incumbent upon professionals to promote and assist all efforts to reduce tobacco consumption. ${ }^{1}$ General population surveys have shown a significant association between psychiatric symptoms and smoking. ${ }^{2,3}$ Lasser et $a l .{ }^{3}$ showed that patients with a mental illness were about twice as likely to smoke as other persons, on the basis of the National Comorbidity Survey population data. In addition it was reported that the $41 \%$ of persons who reported having mental illness in the past month were current smokers and represented $40.6 \%$ of

1*Senior Dental Officer (Special Needs), South Devon Healthcare NHS Trust, Midvale Clinic, Midvale Road, Paignton, Devon TQ4 5BD.

"Correspondence to: Dr Robert Baker

Email: robert.baker@nhs.net

\section{Refereed Paper}

Received 24.11.03; Accepted 07.04.04

doi: 10.1038/sj.bdj.4812299

() British Dental Journal 2005; 198: 529-531 all current smokers in the US. Studies of selected populations of patients with mental and behavioural disorders have also shown high rates of smoking. ${ }^{4,5}$ Positive associations between psychiatric disorders, eg depression, and smoking have been noted in epidemiological studies. ${ }^{6,7}$ Patients with mental and behavioural disorders who smoke, as might be anticipated, have a higher risk of tobacco related medical illness. Smoking related fatal disease is significantly more prominent than in the general population. ${ }^{8}$ It is therefore unfortunate that those of our patients who have perhaps the most to gain from smoking cessation those with mental and behavioural disorders - have by and large, been omitted from dental postgraduate education.

The reader without a background in psychiatry should be aware of two important points.

Firstly there are internationally accepted criteria for the diagnosis of psychiatric disorders published in the Diagnostic and Statistical Manual of Mental Disorders IV, ${ }^{9}$ which readily permit identification and comparisons of psychiatric diseases. Secondly, most patients diagnosed with mental and behavioural disorders are living within the general community (accessing general dental practices) and should not be confused with those even more unfortunate patients with the same disorders who are institutionalised and have an even higher rate of smoking. ${ }^{10}$
An unrecognised problem in this area for dentists

There is a strong relationship between smoking and mental and behavioural disorders. Patients with these disorders have a higher rate of tobacco use due to the effects of smoking, and in turn these disorders affect the patients' ability to quit. An understanding of this will alter the dental management of these patients: many will choose to refer these patients for smoking cessation advice.

\section{Why smoking rates are higher}

The smoking rates are higher for patients with mental and behavioural disorders for five reasons:

- Neurobiological factors

- Genetic factors

- Enzyme induction

- Exposure to trauma

- Self medication.

These factors will affect smoking cessation management in this population.

\section{Neurobiological factors}

The neurobiology of patients with mental and behavioural disorders is affected by the chemicals contained in tobacco. Nicotine acts on the dopamine receptor system, ${ }^{5,11}$ and non-nicotine chemicals inhibit monoamine oxidase type B, enhancing the induction of dopamine transmission. 


\section{Genetic factors}

Common genetic factors may predispose to both smoking and depression, ${ }^{12}$ and also smoking and schizophrenia. ${ }^{13}$

\section{Enzyme induction}

Induction of the P450 liver enzymes by metabolism of tobacco tars, benzopyrenes, in the liver increases the rate of metabolism of some psychiatric medications. Smokers are therefore prescribed higher levels of neuroleptic medication than nonsmokers, otherwise their blood levels of medication would be suboptimal. ${ }^{14,15}$

\section{Exposure to trauma}

Exposure to trauma as seen in post-traumatic stress disorders increases the level of substance abuse, including cigarette smoking as part of the maladaptive behaviour. ${ }^{16}$

\section{Self medication}

Self-medication has been hypothesised, since neurophysiological deficits such as eye-tracking abnormalities in schizophrenia may be improved by nicotine use. ${ }^{20}$ Glynn and Sussman state, as quoted by Goff et al., ${ }^{14}$ that smokers report that smoking reduces the side effects of medication. ${ }^{15}$ Smoking may also reduce dysphoria. $^{7}$

\section{Why quit rates are lower}

Individuals with mental and behavioural disorders (or for depression, merely a history of depression) ${ }^{7}$ have significantly lower quit rates than individuals with no mental illness. ${ }^{3}$ Glassman ${ }^{6}$ reports a difference of $14 \%$ for patients with a lifetime diagnosis of major depression and 31\% for patients without a psychiatric diagnosis. This may be because of the impact of mental and behavioural disorders on motivation.

The internal determinants of treatment motivation, both before and during treatment, have been described by Driescher et al. ${ }^{17}$ as:

- Level of suffering

- Outcome expectancy

- Problem recognition

- Perceived suitability of treatment

- Perceived cost of treatment

- Perceived external pressure.

These are thought to be inter-related. It will be readily appreciated that smokers with mental and behavioural disorders may have differing perceptions to those without.

\section{Level of suffering}

Many of the symptoms of mental and behavioural disorders, such as the apathy of depression and the hallucinations and delusions suffered in schizophrenia ${ }^{18}$ are so

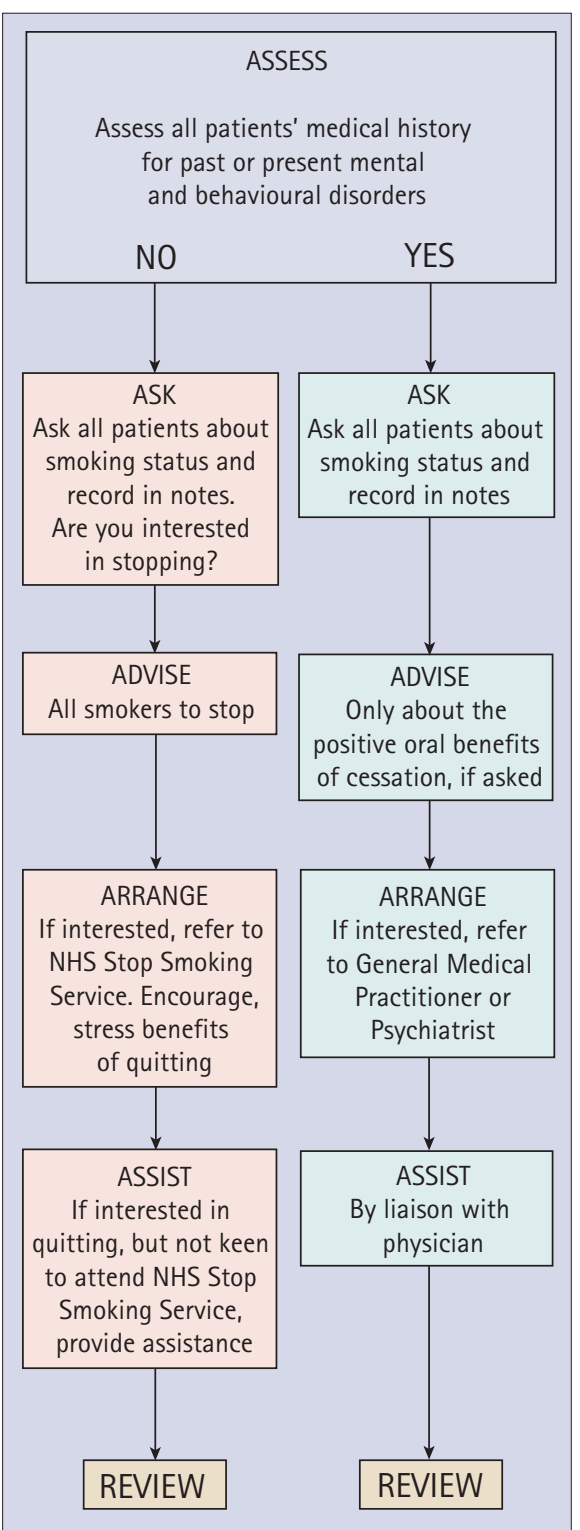

Fig. 1 Proposed management of smoking cessation

terrible for the patient that the minor symptoms suffered before major smoking related illness develops may not be important.

\section{Outcome expectancy}

Patients with depression and anxiety report low levels of self-esteem and energy which in turn can lead to hopelessness. ${ }^{18}$ Their failure to believe that they will quit, reinforced by previous failure(s) to quit and learned helplessness, may reduce their motivation to try. ${ }^{19}$

\section{Problem recognition}

Many patients with mental and behavioural disorders may not view smoking as a problem because they obtain a benefit from it, for example reduced eye-tracking in schizophrenia or relief of dysphoria in depression. ${ }^{18}$

\section{Perceived suitability of treatment}

It has been theorised that patients manage their symptoms by smoking ${ }^{20}$ and it is known that depression developing following cessation disappears within hours of resumption of cigarette smoking in case evidence. ${ }^{6}$

\section{Perceived cost of treatment}

Withdrawal symptoms, such as anxiety, irritability, insomnia, restlessness and depression may be mistaken for other mental and behavioural disorders, or appear to make existing conditions worse. ${ }^{15}$ Changes in psychiatric medication produced by cessation of smoking can cause unwanted side effects such as tremor, or neuroleptic induced Parkinsonism, akathisia, depression and insomnia. ${ }^{15}$ Glassman et al. ${ }^{21}$ suggest that nicotine alters vulnerability to depression: relapse of depression, ${ }^{6,7}$ bipolar disorder, alcohol abuse and drug abuse disorders are associated with smoking cessation. ${ }^{15,21,22}$

\section{Perceived external pressure}

Many disease processes involved in mental and behavioural disorders result in alteration to the patient's thought processes. Patients with schizophrenia suffer from delusions and changes in thinking and perception. Patients with depression may find group processes threatening ${ }^{23}$ and have reduced attention and concentration. $^{18}$ It must therefore be difficult to judge each individual's response to external pressure.

It has been theorised and there is evidence in patients with depression ${ }^{4}$ that as the rate of smoking falls in the general population, there is a rise in the proportion of the smoking population with psychiatric disorders. However mental illness should be seen as a complicating factor to the success of cessation, not an excuse not to try.

\section{Management of smoking cessation for patients with mental and behavioural disorders}

The management of smoking cessation therapy for these patients is more complicated. Careful prior assessment and written planning is required. Guidelines published in the US ${ }^{15}$ and Australia ${ }^{24}$ suggest that all such patients should be monitored by the managing physician. Regular assessments should be made of: their smoking status, their readiness to quit (although it appears that most psychiatric patients are not ready to make an attempt) ${ }^{15}$ and the risks of cessation; cessation advice should be given as appropriate.

Patients with current depression will require management prior to cessation, ${ }^{15}$ and it may be necessary to restart psychotherapy or pharmacotherapy for 
patients whose depression intensified with previous cessation. ${ }^{15}$ They will also require management during the cessation attempt. 'Psychiatric casualties' ie patients who suffer a deterioration in their psychological status from smoking cessation may be expected $;^{6}$ Glassman quotes figures of $2 \%$ for patients with no psychiatric diagnosis compared to $18 \%$ for patients with major depression. These patients may reverse this by being advised to resume smoking again.

A simple quit message may be inadequate. Most of the research work on smoking cessation has been done on patients without mental or behavioural disorders, ${ }^{15}$ but what evidence there is suggests that a combination of different therapies is required, for example a combination of nicotine replacement and antipsychotic medication. ${ }^{15,24,24}$

Blood levels of neuroleptic drugs will change with cessation and will need to be monitored during the attempt. ${ }^{15}$ Bupropion [Zyban] alone may not be suitable for patients with schizophrenia since it may precipitate or exacerbate psychosis, ${ }^{24}$ but used with atypical antipsychotics will encourage smoking cessation. ${ }^{20}$

\section{The quit message}

Usual quit messages may not be appropriate for this group of patients because many patients with mental and behavioural disorders have higher levels of anxiety than the general population. Janis and Feshbach $^{26}$ investigated the effects of different levels of emotionality of an oral health message about dental pain and cancer. This suggested that a message can be too powerful to achieve its purpose. High anxiety individuals are consistently less influenced by strong fear appeal than low anxiety individuals. It has been proposed that there is a link with the Yerkes-Dodson 'Law of Arousal'. ${ }^{19}$ This states that extreme arousal reduces effective action as the person is too agitated to act effectively. Motivational advice should avoid fear-arousing statements about agonising death. These are likely to have a 'boomerang effect' by creating defensive reactions such as inattentiveness, mishearing and repression of ideas.

\section{The dental role}

With recent advances in this field it is now understood that this group will require a level of specialised management, which for many dentists will be beyond their abilities. In fact it would be possible for well-inten- tioned, but misguided, advice to do harm to these patients by: altering the blood levels of neuroleptic drugs (with the consequent side effects); failure to identify and manage appropriately the symptoms of withdrawal; and creating unrecognised psychiatric casualties. Perhaps the challenge of the dental management of these patients is sufficient without undertaking an additional role for which we are not qualified.

However, what matters is the best interests of our patients: we may have to recognise that we can improve our patients' care by not undertaking this role. I would suggest that we should modify our practice as suggested by Schmitz et al. ${ }^{2}$ Prior to including smoking cessation advice within a treatment plan, the dentist should review the medical history, especially the drug history, (patients will often include a medication, but omit mention of a disorder they may feel is embarrassing) to identify these patients. If there is a history of past or present mental and behavioural disorders then the usual smoking cessation advice should be omitted. Instead we should offer: advice relating to the positive, specific dental benefits of cessation; referral to a more appropriate source of smoking cessation management; subsequent close liaison between the dentist and the patient's physician or psychiatrist.

\section{CONCLUSION}

All smokers may benefit from education about the hazards of smoking and cessation therapy. They should have access to the best treatment. Patients with mental and behavioural disorders may benefit the most, however this group has been largely ignored by the dental profession to date. As a profession we should make an effort to acquire evidence based training in appropriate management of all our patients' needs. At present there have been few studies of the management of smokers with mental and behavioural disorders and more research is required. Further research and subsequent education of dentists in smoking cessation management should help more of our patients successfully quit.

1. Watt $\mathrm{R}$, Robinson M. Helping smokers to stop, a guide for the dental team. pp 1-11. London: Health Development Agency, 2004

2. Schmitz N, Kruse J, Kugler J. Disabilities, Quality of life, and mental disorders associated with smoking and nicotine dependence. Am J Psychiatry 2003; 160: 9: 1670-1676.

3 Lasser K, Boyd J W, Woolhandler S, Himmelstein D U, McCormack D, Bor D H. Smoking and mental illness a population-based prevalence study. JAMA 2000; 284: 2606-2610.
4. Murphy J M, Horton N J, Monson R R, Laird N M, Sobel A M, Leighton A H. Cigarette smoking in relation to depression: historical trends from the Stirling county study. Am J Psychiatry 2003; 160: 9: 1663-1669.

5. Kelly C, McCreadie R G. Smoking habits current symptoms, and premorbid characteristics of schizophrenic patients in Nithsdale, Scotland. Am J Psychiatry 1999: 156: 1751-1757.

6. Glassman A H. Cigarette smoking: implications for psychiatric illness. Am J Psychiatry1993; 150: 546-553.

7. Glassman A H, Helzer J E, Covey LS, Stetner F, Tipp J E, Johnson J. Smoking, smoking cessation, and major depression. JAMA 1990; 264: 1546-1549.

8. Brown S, Inskip H, Barraclough B. Causes of excess mortality of schizophrenia. British Journal of Psychiatry 2000; 177: 212-217.

9. American Psychiatric Association. Diagnostic and Statistical Manual of Mental Disorders 4th Edition Text Revision DSM-IV-TR. Washington DC: American Psychiatric Association, 2000.

10. Meiklejohn C, Sanders K, Butler S. Physical health care in medium secure services. Nursing Standard 2003: 17: 33-37.

11. Clarke P B S. Tobacco smoking, genes and dopamine. Lancet 1998; 352: 84-85.

12. Dierker L C, Avenevoli S, Stolar M, Merikangas K R. Smoking and depression: an exanination of the mechanisms of comorbidity. Am J Psychiatry 159: 947-953.

13. McEvoy J P. Schizophrenia, substance misuse, and smoking. Current Opinion in Psychiatry 2000; 13: 15-19.

14. Goff D C, Henderson D C, Amico E. Cigarette smoking in schizophrenia: relationship to psychopathology and medication side effects. Am J Psychiatry 1992: 149: 1189-1194.

15. American Psychiatric Association. Practice guidelines for the treatment of patients with nicotine dependence. Am J Psychiatry 1996; 153: 10 supplement

16. Lee $A$, Isaac $M$, Janca $A$, Post-traumatic stress disorder and terrorism. Current Opinion in Psychiatry 2002: 15: 633-637.

17. Drieschner K H, Lammers S M M, van der Staak C P F. Treatment motivation: An attempt for clarification of an ambiguous concept Clinical Psychology Review 2004; 23: 1115-1137.

18. Puri B K. Psychiatry 2nd ed. pp 85-114. Edinburgh: W B Saunders, 2000.

19. Hayes N. Foundations of Psychology. pp421-471 and 603-621. London: Routledge, 1994.

20. McEvoy J P, Allen T B. Substance abuse (including nicotine) in schizophrenic patients. Current Opinion in Psychiatry 2003; 16: 199-205.

21. Glassman A H, Covey LS, Stetner F, Rivelli S, Smoking cessation and the course of major depression: a follow up study. Lancet $2001 ; 357$ : 1929-1932.

22. Morton K, Pradhan S C. Smoking cessation and major depression. Lancet 2001; 358: 1011

23. Mclntosh C, Ritson B. Treating depression complicated by substance misuse. Advances in Psychiatric Treatment 2001; 7: 357-364.

24. Strasser K, Moeller-Saxone K, Meadows G, Hocking $B$, Stanton J, Kee P, Smoking cessation in schizophrenia, general practice gudelines. Australian Family Physician 2002 31: 21-24

25. Hayford KE, Patten C A, Rummans TA, et al. Efficacy of buproprion for smoking cessation in smokers with a history of major depression or alcoholism. British Journal of Psychiatry 1999; 174: 173-178.

26. Janis I L, Feshbach S, Effects of fear-arousing communications. The Journal of Abnormal and Social Psychology 1953; 48: 78-92. 